\title{
Surgery for primary intracerebral haemorrhage: is it safe and effective?
}

\author{
Talukder $\mathrm{MMH}^{1}$, Islam $\mathrm{KMT}^{2}$, Hossain $\mathrm{M}^{2}$, Jahan $\mathrm{MU}^{3}$, Mahmood $\mathrm{E}^{4}$, Hossain $\mathrm{SS}^{4}$ \\ ${ }^{I}$ Sadar Upazila, Rajbari, ${ }^{2}$ Department of Neurosurgery, Bangabandhu Sheikh Mujib Medical \\ University (BSMMU), Dhaka, ${ }^{3}$ Department of Radiology and Imaging, BSMMU, Dhaka, \\ ${ }^{4}$ Department of Neurosurgery, Dhaka Medical College, Dhaka. \\ Email:tmoajjam@gmail.com
}

\begin{abstract}
This prospective study was conducted to compare the outcome between medical and surgical treatment of primary intracerebral haemorrhage at the department of Neurosurgery, Dhaka Medical College Hospital from January 2006 to October 2007. All patients with primary intracerebral haematoma with Glasgow Coma Scale (GCS) 5-15 (on admission) and heamatoma volume $30 \mathrm{cc}$ or above admitted at Neurosurgery department managed conservatively or surgically were included in this study. Total 60 patients were selected, of them 30 patients managed conservatively and 30 patients managed surgically. Conservatively managed patients regarded as control group (Group-A) and surgically managed patients regarded as experimental group (Group-B). Patients or attendants refused to operate were included in the conservative group. All the selected patients were evaluated on the basis of detailed history, clinical examination (general and neurological examination) and CT scan findings. Outcome was evaluated in term of Glasgow Outcome Scale (GOS). Best medical treatment was given for conservative group and operations were done for surgical group and followed up after surgery till discharge by observing GCS and GOS at discharge. Number of death were 15 (50\%) patients in groupA and 13 (43\%) patients in group-B. There was no significant difference in mortality rate between two groups but outcome was relatively better in group-B. According to Glasgow Outcome Scale, dependency in group-A and group-B was $26.6 \%$ and $23.4 \%$ respectively. So dependency were more in group-A. But there was no significant difference statistically. Seven (23.4\%) patients were independent in group-A but $10(43.3 \%)$ patients were independent in group-B. However in relative terms of outcome of group-B was better than that of group-A. In our study we found no statistically significant difference in outcome between medical and surgical management of primary intracerebral haemorrhage.
\end{abstract}

\section{Introduction}

Spontaneous intracerebral haemorrhage leads to blood clot in brain parenchyma in the absence of trauma or surgery. Spontaneous intracerebral haemorrhage $(\mathrm{SICH})$ can be classified as either primary or secondary depending on underlying cause of haemorrhage. Primary intracerebral haemorrhage $(\mathrm{PICH})$ accounts for approximately $70-80 \%$ of cases and is due to spontaneous rupture of small vessels damaged by hypertension or amyloid angiopathy. Secondary ICH is associated with a number of congenital or acquired condition such as vascular anomalies, coagulopathies, tumors and various drug therapies. Most frequent site for spontaneous intracerebral haemorrhage are the basal ganglia, thalamus, subcortical whitematter of cerebral lobes, cerebellum and brainstem ${ }^{\mathbf{1}}$.

Spontaneous intracerebral haemorrhage accounts for approximately $4-14 \%$ of all strokes and is associated with a high mortality and morbidity. Between $32 \%$ and $50 \%$ of patients die within the first month, and only $20 \%$ are independent after six months of intracerebral bleeding ${ }^{2}$.

The incidence of ICH increases significantly after age 55 and doubles each decade of age till 80, at which point the incidence increases 25 fold during each decade $\mathbf{3}^{3}$.

Many other factors can contribute to bleeding like acute increase in blood pressure and flow may also be important particularly where auto regulation may be compromised (as in trauma) or where pressure may be above the limit of auto regulation, as in toxemia. SICH generally occurs during the morning or early afternoon when a patient is active. Therefore it has been postulated that the trigger for bleeding may be a diurnal rise or an acute increase in blood pressure from whatever cause $e^{4}$. 
Cerebral amyloid angiopathy (CAA) is the other major cause of primary SICH and an important cause of lobar ICH in elderly population.

Hypertension has been clearly identified as the major risk factor for $\mathrm{ICH}$, but the presence of this pre morbid hypertension has ranged in various studies from $26 \%$ to $89 \%$ of the patients. The true figure is probably about $50 \%$.

Diabetes is an important risk factor for mortality after intracerebral haemorrhage (ICH). ICH in diabetic patients present some different clinical features from $\mathrm{ICH}$ in non diabetic patients; accordingly this subgroup of patients should be very closely monitored ${ }^{6}$.

Most spontaneous haematomas are attributed to chronic arterial hypertension. Other potential risk factors for ICH include alcohol consumption, anticoagulant treatment and to a lesser extent, aspirin use, thrombolytic therapy and the use of amphetamines or cocaine ${ }^{7}$.

In one fourth of patients with intracerebral hemorrhage who are initially alert, deterioration in the level of consciousness occurs within the first 24 hours after onset of the hemorrhage. The presence of a large hematoma and ventricular blood increases the risk of subsequent deterioration and death. Expansion of the hematoma is the most common cause of underlying neurologic deterioration within the first three hours after the onset of hemorrhage. Worsening cerebral edema is also implicated in neurologic deterioration that occurs within 24 to 48 hours after the onset of hemorrhage. Infrequently, late deterioration is associated with progression of oedema during the second and third week after the onset ${ }^{\mathbf{8}}$.

Treatment of haemorrhagic stroke is based on underlying cause of the haemorhage and extent of damage to brain. The initial management of all patient with spontaneous ICH consists of medical management and stabilization, followed by either surgical intervention or conservative treatment. The goals of medical treatment includes control of hypertension, reduction of intracranial pressure and prevention of seizures. Controversy exists concerning the indications for operative treatment of spontaneous ICH and decisions should be individualized. Several criteria may be used to select appropriate patient for surgical treatment. Among them the important consideration are the patient's level of consciousness, site and size of haematoma, involvement of dominant hemisphere, deterioration of neurological status, midline shift and ventricular extension, proper timing of surgery'.
The most significant predictors of mortality are haematoma volume and level of consciousness at admission. Increasing patient's age, infratentorial location of the ICH, midline shift and presence of intraventricular blood have all been associated with poor outcome. In addition, intubation has been shown to be an independent predictor of mortality in ICH. On admission Glasgow Coma Scale of 8 or less and ICH haematoma volume of $60 \mathrm{~m} 1$ or more predicted a mortality of $91 \%$ at 30 days. Some investigations have reported that a haematoma volume of $50 \mathrm{~m} 1$ was associated with a mortality rate of $90 \%$. A rating system known as the ICH score has been developed. It is based on GCS, age, haematoma volume, location and presence of intraventricular blood ${ }^{10}$.

With Population of more than 143 million, increasing life expectancy and improvement of diagnostic facilities including availability of CT scan in many district centers contributes in increase in the number of detection of intracerebral haemorrhage patients. The place of surgery in the treatment of intracerebral haematoma is still controversial. Controversy exists about medical and surgical management which is better still in the modern CT era \& in minimally invasive surgery period. So it is our small effort to overcome the controversy.

\section{Materials and Methods}

This prospective study was carried out at the department of Neurosurgery, Dhaka Medical College Hospital, Dhaka, Bangladesh from January 2006 to October 2007. All patients with primary intracerebral haematoma with GCS 5-15 (on admission) and heamatoma volume $30 \mathrm{cc}$ or above admitted at Neurosurgery department managed conservatively or surgically were included in this study. Total 60 patients were selected, of them 30 patients managed conservatively and 30 patients managed surgically. Conservatively managed patients regarded as control group (Group-A) and surgically managed patients regarded as experimental group (Group-B). Patients or attendants refused to operate were included in the conservative group. All the selected patients were evaluated on the basis of detailed history, clinical examination (general and neurological examination) and CT scan findings. Outcome was evaluated in term of Glasgow Outcome Scale (GOS). Best medical treatment was given for conservative group and operations were done for surgical group and followed up after surgery till discharge by observing Glasgow Coma Scale (GCS) and Glasgow Outcome Scale (GOS) at discharge. 


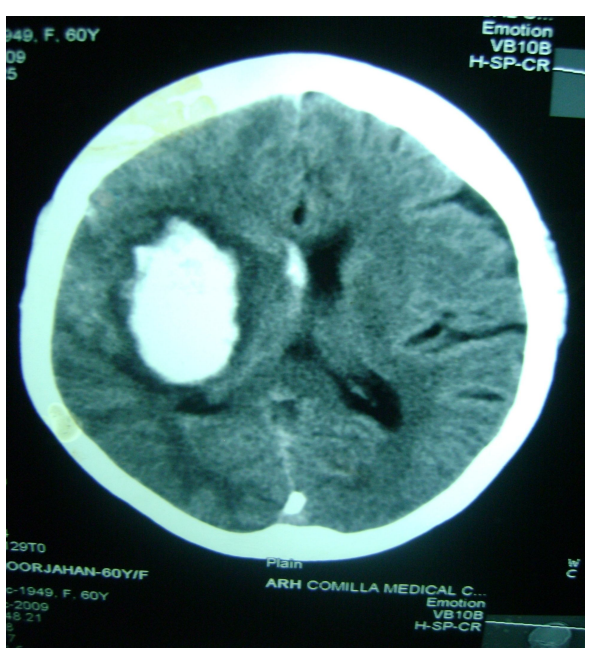

Plate-I: Preoperative CT scan of right basal ganglia haemorrhage with midline shift and ventricular extension.

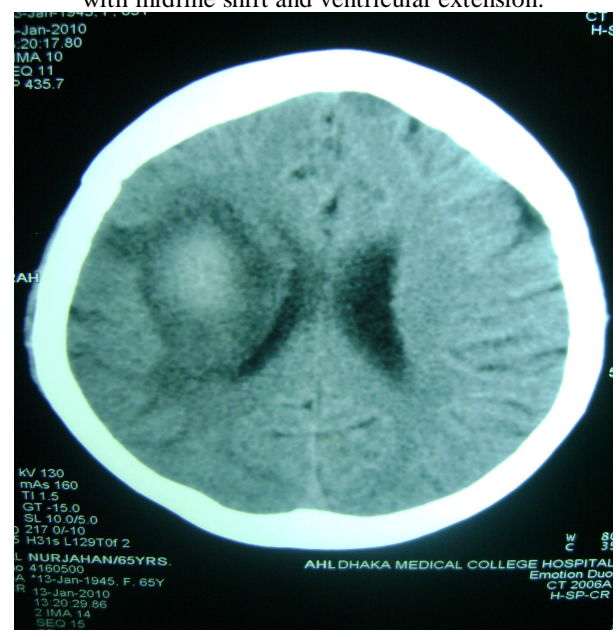

Plate II: Postoperative CT scan after craniotomy \& evacuation of haematoma

A pre-designed data collection sheet was prepared including the variable of age and sex of the patients, clinical presentations, GCS at admission and discharge, Glasgow outcome scale at discharge, volume \& site of hematoma on CT and history of hypertension. The data was collected by the researcher himself.

Data was collected and edited manually. A master sheet was prepared and data was analyzed by using Statistical Package for Social Science (SPSS) program. $\chi^{2}$ test was used to compare the outcome between medical and surgical treatment of primary intracerebral haemorrhage. $p$ value $<0.05$ was considered as a minimum level of significance.

\section{Results}

The age of total 60 patients ranged from 30 to 85 years. Means age of group-A and group-B were 57 years and 55 years respectively. Highest number of patients were in 51 to 60 age group (33\%). There were 18 male and 12 female patients in group-A and 15 male and 15 female patients in group-B.
Table I: GCS score on admission

\begin{tabular}{cccccc}
\hline \multirow{2}{*}{$\begin{array}{c}\text { GCS on } \\
\text { admission }\end{array}$} & \multicolumn{2}{c}{ Groups } & & & \\
\cline { 2 - 3 } & $\begin{array}{c}\text { Conservative } \\
\text { group-A }\end{array}$ & $\begin{array}{c}\text { Surgical } \\
\text { group-B }\end{array}$ & Total & $X^{2}$ & P-value \\
\hline 5 & 4 & 7 & 11 & & \\
6 & 3 & 5 & 8 & & \\
7 & 5 & 3 & 8 & & \\
8 & 2 & 6 & 8 & & \\
9 & 3 & 3 & 6 & & \\
10 & 3 & 2 & 5 & 7.885 & 0.546 \\
11 & 4 & 2 & 6 & & \\
12 & 2 & 0 & 2 & & \\
13 & 1 & 0 & 1 & & \\
14 & 1 & 2 & 3 & & \\
15 & 2 & 0 & 2 & & \\
\hline Total & 30 & 30 & 60 & & \\
\hline
\end{tabular}

Maximum patients' GCS score was low on admission. GCS of group-B patients were relatively low because deterioration of GCS level were the indication of ICH operation in some instant. Pvalue indicate that there were no significant difference.

Table II: Location of haematoma on CT scan

\begin{tabular}{|c|c|c|c|c|c|}
\hline \multirow[b]{2}{*}{ Site haematoma } & \multicolumn{2}{|c|}{ Groups } & \multirow[b]{2}{*}{ Total } & \multirow[b]{2}{*}{$\chi^{2}$} & \multirow{2}{*}{$\begin{array}{c}\mathrm{P}- \\
\text { value }\end{array}$} \\
\hline & $\begin{array}{c}\text { Conservative } \\
\text { group-A }\end{array}$ & $\begin{array}{l}\text { Surgical } \\
\text { group-B }\end{array}$ & & & \\
\hline Frontal & 3 & 1 & 4 & \multirow{10}{*}{9.0} & \multirow{10}{*}{0.436} \\
\hline Parietal & 5 & 5 & 10 & & \\
\hline Temporal & 1 & 3 & 4 & & \\
\hline Basal ganglia & 9 & 4 & 13 & & \\
\hline Temporoparietal & 8 & 6 & 14 & & \\
\hline Parietooccipital & 0 & 1 & 1 & & \\
\hline Posterior fossa & 1 & 4 & 5 & & \\
\hline Frontoparietal & 1 & 3 & 4 & & \\
\hline Occipital & 2 & 2 & 4 & & \\
\hline Temporobasal & & 1 & 1 & & \\
\hline Total & 30 & 30 & 60 & & \\
\hline
\end{tabular}

Basal ganglia and temperoparietal site were predominant. Distribution of site in both group were more or less similar $(\mathrm{P}=0.436))$. So they did not influence the outcome.

Table III: Volume of haematoma

\begin{tabular}{cccccc}
\hline $\begin{array}{c}\text { Volume of } \\
\text { haematoma }\end{array}$ & $\begin{array}{c}\text { Conservative } \\
\text { group-A }\end{array}$ & $\begin{array}{c}\text { Surgical } \\
\text { group-B }\end{array}$ & Total & $\chi^{2}$ & $\begin{array}{c}\text { P- } \\
\text { value }\end{array}$ \\
\hline 30 to39 & 2 & 6 & 8 & & \\
40 to49 & 9 & 6 & 15 & 2.848 & 0.416 \\
50 to 59 & 7 & 8 & 15 & & \\
$>60$ & 12 & 10 & 22 & & \\
\hline Total & 30 & 30 & 60 & & \\
\hline
\end{tabular}

Volume distribution in two groups almost equal so they did not modify the outcome significantly $(\mathrm{P}=0.416)$.

Table IV: Ventricular extension of haematoma

\begin{tabular}{lccccc}
\hline $\begin{array}{l}\text { Ventricular } \\
\text { extension }\end{array}$ & $\begin{array}{c}\text { Group- } \\
\text { A }\end{array}$ & $\begin{array}{c}\text { Group- } \\
\text { B }\end{array}$ & Total & $\begin{array}{c}\chi^{2} \text { with } \\
\text { Yates } \\
\text { correction }\end{array}$ & $\begin{array}{c}\text { P- } \\
\text { value }\end{array}$ \\
\hline Yes & 4 & 2 & 6 & 0.185 & 0.667 \\
No & 26 & 28 & 54 & & \\
\hline
\end{tabular}


No difference ( $\mathrm{p}$-value with Yates correction= 0.667) of ventricular extension between two groups, so ventricular extension had no influence on outcome.

Table V: Mortality at discharge

\begin{tabular}{|c|c|c|c|c|c|}
\hline \multirow[b]{2}{*}{ Mortality } & \multicolumn{2}{|c|}{ Groups } & \multirow[b]{2}{*}{ Total } & \multirow[b]{2}{*}{$\chi^{2}$} & \multirow[b]{2}{*}{$\begin{array}{c}\text { P- } \\
\text { value }\end{array}$} \\
\hline & $\begin{array}{l}\text { Conservative } \\
\text { group-A }\end{array}$ & $\begin{array}{l}\text { Surgical } \\
\text { group-B }\end{array}$ & & & \\
\hline Alive & 15 & 17 & 32 & \multirow{2}{*}{0.268} & \multirow{2}{*}{0.605} \\
\hline Death & 15 & 13 & 28 & & \\
\hline Total & 30 & 30 & 60 & & \\
\hline
\end{tabular}

Mortality is one of our outcome determinant. In group-A mortality rate was 50\% (15 patients) and survival rate was $50 \%$ (15 patients). On the other hand in group-B $13(43.3 \%)$ patients died, survival rate was $56.6 \%$ (17 patients). The outcome of mortality was nonsignificant $(\mathrm{P}=0.605)$.

Table VI: GCS (Pre-Operative) comparison

\begin{tabular}{cccc}
\hline GCS Level & Group-A & Group-B & Total \\
\hline$\geq 9$ & 16 & 9 & $25(40 \%)$ \\
$<9$ & 14 & 21 & $35(60 \%)$ \\
\hline
\end{tabular}

In Group-A 16 patients had GCS $\geq 9$ and 14 patients had GCS $>9$, in group-B 9 patients had GCS $\geq 9$ and 21 patients had GCS >9. GCS is the important predictor in the outcome of $\mathrm{PICH}$. In our study GCS is more worse in group-A but it was not significant $(\mathrm{P}=0.546)$.

Table VII: GCS score at discharge

\begin{tabular}{lccccc}
\hline \multirow{2}{*}{$\begin{array}{c}\text { GCS at } \\
\text { Discharging }\end{array}$} & $\begin{array}{c}\text { Conservative } \\
\text { group-A }\end{array}$ & $\begin{array}{c}\text { Surgical } \\
\text { group-B }\end{array}$ & Total & $\chi^{2}$ & $\begin{array}{c}\text { P- } \\
\text { value }\end{array}$ \\
\hline 10 & 1 & 1 & 2 & & \\
12 & 4 & 1 & 5 & & \\
13 & 0 & 1 & 1 & 3.743 & 0.587 \\
14 & 2 & 2 & 4 & & \\
15 & 8 & 12 & 20 & & \\
\hline Total & 15 & 17 & 32 & & \\
\hline
\end{tabular}

GCS at discharge in both groups were more or less similar indicated by statistical result $(\mathrm{P}=0.587)$.

Table VIII: Comparison of outcome in Glasgow Outcome Scale

\begin{tabular}{|c|c|c|c|c|c|}
\hline \multirow[b]{2}{*}{ GOS } & \multicolumn{2}{|c|}{ Groups } & \multirow[b]{2}{*}{ Total } & \multirow[b]{2}{*}{$\chi^{2}$} & \multirow{2}{*}{$\begin{array}{c}\mathrm{P}- \\
\text { value }\end{array}$} \\
\hline & $\begin{array}{c}\text { Conservative } \\
\text { group-A }\end{array}$ & $\begin{array}{l}\text { Surgical } \\
\text { group-B }\end{array}$ & & & \\
\hline Good & 0 & 3 & 3 & & \\
\hline Moderate disability & 7 & 7 & 14 & & \\
\hline Severe disability & 8 & 7 & 15 & 3.210 & 0.360 \\
\hline Vegetative state & 0 & 0 & 0 & & \\
\hline Death & 15 & 13 & 28 & & \\
\hline Total & 30 & 30 & 60 & & \\
\hline
\end{tabular}

In group-A $15(50 \%)$ patients died, 8(26.7\%) patients had severe disability and $7(23.3 \%)$ patients had moderate disability.

In group-B $13(43.3 \%)$ patients died $7(23.3 \%)$ patients had severe and $7(23.3 \%)$ patients had moderate disability and $3(10 \%)$ patients had good outcome. Statistically the result was nonsignificant as because $\mathrm{p}$-value was $0.360(>0.05)$.

Table IX: GOS comparison in terms of death and dependent and independent.

\begin{tabular}{|c|c|c|c|c|}
\hline \multirow{2}{*}{$\begin{array}{l}\text { Glasgow outcome } \\
\text { scale }\end{array}$} & \multicolumn{2}{|c|}{ Group-A } & \multicolumn{2}{|c|}{ Group-B } \\
\hline & $\begin{array}{c}\text { Death or } \\
\text { Dependant }\end{array}$ & Independent & $\begin{array}{c}\text { Death or } \\
\text { Dependant }\end{array}$ & Independent \\
\hline Good & & 0 & & 3 \\
\hline Moderate disability & & 7 & & 7 \\
\hline Severe disability & 8 & & 7 & \\
\hline Vegetative state & 0 & & 0 & \\
\hline Death & 15 & & 13 & \\
\hline Total & $23(76.6 \%)$ & $7(23.4 \%)$ & $20(66.6 \%)$ & $10(43.3 \%)$ \\
\hline
\end{tabular}

Number of death were $15(50 \%)$ patients in groupA and 13 (43\%) patients in group-B.

\section{Discussion}

A long controversy exists for last few decades and still continues in this modern CT era regarding conservative versus surgical management of the primary intracerebral haemorrhage (PICH), important considerations are patient's initial level of consciousness, size and location of hematoma, involvement of dominant hemisphere, deterioration of neurologic status and development of hydrocephalus. So decision should be individualized. In our study we tried to find out which group, conservative or surgical had better outcome by Glasgow outcome scale.

Regarding the age of the patients of our study groups they had no significant difference in the mean age of 55 years and 57.86 years \& it correlate with other study ${ }^{11}$ where mean age is 58.8 years.

Regarding the sex, male: female ratio was $1: 1$ in group-A and 3:2 in group-B. So there were no significant variation in two groups.

Regarding hypertension in group-A, 24(80\%) patients had history of hypertension and in groupB, 21(70\%) patients had history of hypertension. Forty five (70\%) patients had history of hypertension which correlates with other study ${ }^{12}$ where $70-90 \%$ of patients had history of hypertension ${ }^{1}$.

Regarding GCS in Group-A 16 patients had GCS $\geq 9$ and 14 patients had GCS $>9$, in group-B 9 patients had GCS $\geq 9$ and 21 patients had GCS $>9$. GCS is the important predictor in the outcome of $\mathrm{PICH}$. In our study GCS is more worse in group-A but it was not significant $(\mathrm{P}=0.546)$.

In both groups, volume of hematoma distribution were all most similar. So had no significant difference between two groups ( $\mathrm{P}=0.416)$. 
In our study number of death were $15(50 \%)$ patients in group-A and 13 (43\%) patients in groupB. There was no significant difference in mortality rate between two groups but outcome was relatively better in group-B. Our mortally rate had similarity with other study $\mathrm{y}^{\mathbf{2 , 1 2}}$.

According to Glasgow Outcome Scale, dependency in group-A and group-B was $26.6 \%$ and $23.4 \%$ respectively. So dependency were more in groupA. But there was no significant difference statistically. Seven (23.4\%) patients were independent in group-A but $10(43.3 \%)$ patients were independent in group-B. However in relative terms of outcome of group-B was better than that of group-A.

Our study almost similar to other study ${ }^{\mathbf{1 3}, \mathbf{1 4}}$. Where surgical management had better outcome but statistically non significant. On the other hand McKissock et al. ${ }^{15}$ and Juvela et al. ${ }^{\mathbf{1 6}}$ support conservative treatment of PICH. But McKissock et al. ${ }^{15}$ trail was done without CT scan findings and diagnosed by clinical examination, angiography and CSF examination. So we think this was the reason behind the poor outcome of their study.

Conclusion: In our study we found no statistically significant difference in outcome between surgical and medical management of primary intracerebral haemorrahge.

\section{References}

1. Fewel ME, Thomoson GB, Hoff JT. Spontaneous intracerebral haemorrhage: a review. Neurosurg Focus. 2003; 15:1-16.

2. Castellanos M, Leira R, Tcjada J, Gil-Peralta A, Dayalos A, Castillo. Predictors of good outcome in medium to large spontaneous supratentorial intracerebral haemorrhages. J Neurol Neurosurg Psychiatry. 2005; 76: 691-95.

3. Aghi M, Ogilvy CS, Carter BS. Surgical management of intracerebral haemorrhage. In: Schmidek and Sweet operative neurosurgical techniques. 5th edn. Saunders: Elsevier: Philadelphia. 2006: 1061-74.

4. Kaufman HH. Spontaneous Intraparenchymal Brain haemorrhage. In: Neurosurgery (eds) Wilkins, RH, Rengachary. $2^{\text {nd }}$ edn. MacGraw-Hill companies. USA. 1996: $2567-85$.
5. Wityk RJ and Caplan LR. Hypertensive intracerebral hemorrhage: epidemiology and clinical pathology. In: Neurosurgery clinics of North America (eds) Winn HR, Mayberge MR. WB. Saunders company. Philadelphia. 1992: 521-32.

6. Juvela S, Hiliborn M, Palomaki FL, Risk factors for spontaneous intracerebral hemorrhage. Stroke. 2003; 26: $1558-64$.

7. Arboix A, Massons J, Garcia-Eroles L, Oileeres M, Trga C. Diabetes Is an Independent Risk Factor for InHospital Mortality From Acute Spontaneous Intracerebral Hemorrhage. Diabetes care. 2000; 23: 1527-32.

8. Qureshi AI, Tuhrim S, Broderick JP, Batjer HH, Hondo H, Hanley DF. Spontaneous intraccrebral haemorrhage. NEJM. 2001; 344: 1450-60.

9. Weiner HL and Cooper PR. The Management of Spontaneous Intracerebral haemorrhage. Contemporary Neurosurgery. 1992; 14:1-8.

10. Butcher $\mathrm{K}$ and Laidlaw J. Current intracerbral haemorrhage management. Journal of clinical neuroscience. 2003; 10: 158-67.

11. Ahmed R, Shakir AH, Moizuddin SM, Haleem A, Ali S, Durrani K. Predictors of In-Hospital Mortality for intracerebral Hemorrhage: A Hospital-Based Study in Pakistani Adults. J Stroke Cerebrovas Dis. 2001; 10 (3): 122-27

12. Brodcrick JP, Adams HP, Barsalan W, Feinberg W, Feldmann E. Guidelines for the management of spontaneous intracerebral haemorrhage: A statement for healthcare professionals from a special writing group of the stroke council. American heart association: Stroke. 1999; 30: 915.

13. Batjer HH, Reisch JS, Allen BC, et al. Failure of surgery to improve outcome in hypertensive putaminal hemorrhage. A prospective randomized trial. Arach Neruol. 1990; 47: 1103-6.

14. Auer LM, Deinsherger W, Niederkorn K, Gell G, Klcinert R, Schncider G, Holzer P, Bone G, Mokry M, $\mathrm{K}$ (umlaut]orner E, et al. Endoscopic surgery versus medical treatment for spontaneous intracerebral hematoma: a randomized study. J Neurosurg. 1989; 70: 530-35.

15. McKissock W, Richardson A, Taylor J. Primary intracerebral haemorrhage. A controlled trial of surgical and conservative treatment on 180 unselected case. Lancet. 1961; 2: 221-26.

16. Juvela S, Heiskanen O, Poranen A, Valtonen S, Kuurne T, Kaste M, Troupp H. The treatment of spontaneous intracerebral hemorrhage: a prospective randomized trial to surgical and conservative treatment. J Neurosurg. 1989; 70: 755-58. 